DOI: https://doi.org/10.47405/mjssh.v5i7.923

\begin{tabular}{|c|c|}
\hline & Malaysian Journal of Social Sciences and Humanities (MJSSH) \\
\hline Malaysian Journal of & Volume 5, Issue 7, July 2020 \\
\hline (MJ-sSH) & e-ISSN : 2504-8562 \\
\hline & $\begin{array}{l}\text { Journal home page: } \\
\text { www.msocialsciences.com }\end{array}$ \\
\hline
\end{tabular}

\title{
Kesan Penggunaan Sumber-Sumber Sejarah Berdasarkan Model Motivasi ARCS Terhadap Peningkatan Motivasi Dalam Kalangan Murid Tingkatan Empat
}

\author{
M. Kaviza ${ }^{1}$ \\ ${ }_{1}^{1}$ Pusat Pengajian Pendidikan dan Bahasa Moden, Universiti Utara Malaysia (UUM) \\ Correspondence: M. Kaviza (kavizakaviza@yahoo.com)
}

\begin{abstract}
Abstrak
Kajian ini bertujuan mengkaji kesan penggunaan sumber-sumber sejarah terhadap peningkatan motivasi dalam kalangan murid Tingkatan Empat. Dalam kajian ini, aktiviti pengajaran dan pembelajaran Sejarah berasaskan penggunaan sumber-sumber sejarah telah direka bentuk berdasarkan Model Motivasi ARCS (Keller, 1983; 1986) sebagai intervensi. Reka bentuk Pra-eksperimen iaitu Ujian Pra-Ujian Pasca Satu Kumpulan telah digunakan dalam kajian ini. Kesan penggunaan sumbersumber sejarah terhadap motivasi diukur dalam ujian pra dan ujian pasca. Seramai 55 orang murid yang ditentukan dengan menggunakan teknik persampelan cluster terlibat sebagai sampel dalam kajian ini. Soal selidik Instructional Material Motivation Survey yang telah diadaptasi telah digunakan dalam kajian ini. Data telah dianalisis secara deskriptif dan inferensi iaitu ujian-t sampel berpasangan. Dapatan kajian menunjukkan bahawa penggunaan sumber-sumber sejarah memberi kesan peningkatan kepada motivasi dalam kalangan murid. Implikasi kajian ini adalah dalam mengintegrasikan penggunaan sumber-sumber sejarah sebagai kaedah pengajaran dan pembelajaran Sejarah yang dapat meningkatkan motivasi dalam kalangan murid.
\end{abstract}

Kata kunci: Model Motivasi ARCS, motivasi, murid Tingkatan Empat, sumber sejarah

\section{The Impact of Using Historical Sources Based ARCS Motivation Model on the Motivation Among Form Four Students}

\begin{abstract}
This study aims at investigating the effect of using historical resources on the motivation among Form Four students. The learning and teaching activities based ARCS Motivation Model was designed as intervention in this study. Pre-Experimental Design: One Group PreTest-PostTest was used in this study. The impact of using historical resources on the motivation were measured in the pre-test and post-test. A sample of respondents comprising 55 students was recruited in this study using cluster and purposive sampling techniques. The adapted Instructional Material Motivation Survey was used in this study. Data were analyzed by descriptive and inference statistics using Pair Sample t-Test. The findings showed that the use of historical resources has an impact on the motivation. The implication of this study is historical resources are potential to implement as teaching and learning method to increase motivation among students.
\end{abstract}

Keywords: ARCS Motivation Model, form four students, historical resources, motivation 


\section{Pengenalan}

Mata pelajaran sejarah yang dijadikan sebagai mata pelajaran wajib lulus dalam peperiksaan Sijil Pelajaran Malaysia (SPM) mulai tahun 2013 merupakan salah satu usaha pemartabatan ilmu sejarah selaras dengan perkembangan sistem pendidikan sejarah pada abad ke-21. Ilmu sejarah merupakan disiplin ilmu yang melibatkan proses penyelidikan tentang sesuatu perkara yang telah berlaku pada masa dahulu yang ditafsirkan dengan menggunakan bahan bukti sejarah (Hazri, 2003; Sunthralingam, 1985). Penggunaan sumber sejarah merujuk kepada penggunaan koleksi bahan-bahan sejarah yang digunakan oleh sejarahwan bagi memahami dan membuktikan interpretasi dan tafsiran yang diberikan terhadap sesuatu peristiwa sejarah tersebut (Hover, Hicks \& Dack, 2016; Wineburg, 1991a; 1991b). Justeru, murid-murid perlu dilibatkan dengan penggunaan pelbagai jenis sumber sejarah yang dapat menjadikan proses pengajaran dan pembelajaran lebih menarik dan menyeronokkan dengan menyediakan peluang untuk meneroka ilmu sejarah dengan mendalam (Johansson, 2017; Reisman \& Fogo, 2015; Patterson, Lucas \& Kithinji, 2002).

\section{Latar Belakang Kajian}

\section{Sumber Sejarah}

Sumber sejarah telah ditakrifkan sebagai sebuah karya yang menyediakan maklumat atau bukti yang bersifat asli yang berkaitan dengan sesuatu fakta, kejadian atau siri sesuatu peristiwa yang berlaku pada masa lalu yang dijadikan bahan kajian oleh ahli sejarah (Suntharalingam, 1985). Terdapat dua jenis sumber sejarah iaitu sumber primer dan sumber sekunder. Sumber primer iaitu merujuk kepada sumber seperti catatan, laporan, surat, buku harian, dokumen, rekod dan sebagainya yang bersifat asli yang dapat memberikan maklumat, catatan atau melaporkan mengenai sesuatu peristiwa yang berlaku, manakala sumber sekunder pula dirujuk sebagai sumber yang tidak asli yang dihasilkan melalui penulisan sejarahwan tentang sesuatu peristiwa sejarah berpandukan kepada sumber primer seperti ensiklopedia, majalah, buku teks, risalah dan sebagainya (Hazri, 2003; Suntharalingam, 1985). Dalam kurikulum Sejarah, terdapat satu struktur disiplin sejarah yang sistematik dan tersendiri yang dapat mengembangkan proses pengajaran dan pembelajaran sejarah yang lebih dinamik (PPK, 2003) iaitu inkuiri sejarah, pengumpulan sumber, kemahiran pemikiran sejarah, penjelasan sejarah, pemahaman sejarah dan empati. Oleh itu, sumber sejarah merupakan salah satu elemen yang penting dalam kurikulum sejarah yang perlu diterapkan dalam kalangan murid. Hal ini kerana ilmu sejarah pada asasnya adalah mementingkan kepada pengayaan sumber sejarah dari segi tatacara mendapatkan sumber, punca-punca sumber, pengelasan sumber pertama dan kedua, dan merekodkan bukti-bukti yang diperoleh. Oleh itu, sumber sejarah adalah berpotensi diintegrasikan dalam proses pengajaran dan pembelajaran Sejarah bagi menggalakkan dan meningkatkan kemahiran belajar dan minat dalam kalangan murid (PPK, 2003).

\section{Model Motivasi ARCS}

Motivasi merupakan elemen penting yang perlu diberi perhatian dalam pelaksanaan proses pengajaran dan pembelajaran. Hal ini kerana motivasi memberikan impak positif kepada pencapaian hasil pembelajaran kerana menyumbang kepada pencapaian akademik dalam kalangan murid. Sungguhpun begitu, elemen motivasi mempunyai motivasi mempunyai kaitan dengan bahan instruksi yang digunakan dalam proses pengajaran dan pembelajaran. Dalam kajian ini, pengkaji telah memilih Model Motivasi ARCS (Keller, 1983; 1987) kerana ianya didapati sesuai dan relevan digunakan untuk mereka bentuk aktiviti pengajaran dan pembelajaran Sejarah berasaskan penggunaan sumber sejarah yang dirujuk sebagai bahan pengajaran dan pembelajaran Sejarah di dalam kelas. Hal ini kerana Model Motivasi ARCS (Keller, 1983; 1987) ini telah digunakan secara meluas dari segi reka bentuk aktiviti pengajaran dan pembelajaran, pembinaan dan pengujian bahan-bahan instruksional dan peningkatan penyertaan, sokongan, maklum balas serta penilaian terhadap proses pembelajaran (Aizu, Nor Hasbiah 
\& Norasikin, 2017; Malone \& Lepper; Anselmo \& Sandra, 1981; Carroll, 1963). Penggunaan Model Motivasi ARCS (Keller, 1983; 1987) secara meluas adalah selaras dengan tujuan model tersebut dibangunkan yang berperanan sebagai strategi bagi meningkatkan motivasi murid, khususnya dari aspek penggunaan bahan-bahan pengajaran dan pembelajaran secara efisien dengan memfokuskan kepada aspek mencipta, mensimulasikan dan mengekalkan persekitaran pembelajaran motivasi dalam pembelajaran. Sungguhpun begitu, model ini juga telah menerangkan bahawa murid yang bermotivasi tinggi akan melibatkan diri dengan aktiviti dan tugasan yang diberikan dengan lebih baik atau berkesan sekiranya mereka berpuas hati dengan nilai dan kepentingan sesuatu aktiviti atau tugasan tersebut serta merasakan bahawa mereka yakin dapat menyelesaikan aktiviti dan tugasan yang diberikan. Oleh itu, aktiviti pengajaran dan pembelajaran yang dirancang dan direka bentuk untuk murid-murid perlulah memberikan impak positif dengan meningkatkan keyakinan dalam diri mereka bahawa mereka mampu untuk melakukannya atau menyelesaikannya dengan baik.

Selain itu, empat komponen yang dicadangkan oleh Keller, (1983; 1987) dalam Model Motivasi ARCS adalah seperti berikut:

a) Perhatian (Attention=A) yang merujuk kepada menarik minat dan mengekalkan perhatian dalam kalangan murid serta meningkatkan perasaan ingin tahu kepada penerokaan bahan pengajaran dan pembelajaran yang diberikan.

b) Perkaitan (Relevance $=R$ ) yang merujuk kepada perhubungan antara objektif pembelajaran, minat, motif, tujuan, kegunaan dan kepentingan pembelajaran pada masa hadapan dengan menggunakan bahan-bahan pembelajaran yang diberikan.

c) Keyakinan (Confidence=C) merujuk kepada usaha untuk membina keyakinan dalam pembelajaran serta kemampuan murid-murid dalam menyelesaikan aktiviti dan tugasan pembelajaran yang telah disediakan dalam proses pengajaran dan pembelajaran di dalam kelas.

d) Kepuasan (Satisfaction $=S$ ) yang merujuk kepada aspek kepuasan terhadap aktiviti pembelajaran yang dijalanakan sama ada secara intrinsik mahupun secara ekstrinsik bagi memastikan murid-murid dapat menyelesaikan tugasan-tugasan tersebut dengan berkesan.

Justeru, keempat-empat komponen dalam Model Motivasi ARCS (Keller, 1983; 1987) telah digunakan semasa merancang dan mereka bentuk aktiviti pengajaran dan pembelajaran Sejarah berasaskan penggunaan sumber-sumber sejarah dalam kalangan murid Tingkatan Empat. Hal ini kerana kesemua komponen tersebut perlu dikekalkan pada setiap kali murid-murid mengikuti pengajaran dan pembelajaran Sejarah kerana sekiranya ianya gagal diaplikasikan dengan baik, maka tahap motivasi dalam kalangan murid akan menjadi rendah dan hasil pembelajaran yang diharapkan tidak dapat dicapai. Oleh itu, murid yang bermotivasi tinggi akan sentiasa berusaha secara gigih dan bertanggungjawab terhadap proses pembelajaran mereka kerana mereka percaya bahawa ianya akan memberikan impak positif terhadap pencapaian akademik secara tidak langsung.

\section{Pernyataan Masalah}

Kekurangan motivasi dan minat adalah antara masalah yang sering kali ditimbulkan dalam proses pengajaran dan pembelajaran Sejarah. Perkara ini dibuktikan dengan pendapat Abdul Rahim (2000), Hazri (2003) serta Omardin dan Yunus (1996) yang telah menjelaskan bahawa murid-murid didapati kurang minat dan bermotivasi dengan proses pengajaran dan pembelajaran Sejarah di dalam kelas disebabkan oleh kaedah pengajaran dan pembelajaran yang diamalkan yang menimbulkan kebosanan. Tambahan pula, kedua-dua pendapat tersebut adalah bertepatan dengan kajian-kajian lepas seperti kajian Ch'ng (2005), kajian Fadzillah (2010), kajian Ambika, Maskun dan Suparman (2017) serta kajian Sri Wahyuni dan Anuar (2019) yang telah menjelaskan bahawa murid-murid mendapati bahawa proses pengajaran dan pembelajaran Sejarah yang tidak menarik dan berteraskan penerangan guru telah mengakibatkan tahap motivasi mereka menjadi rendah dan sederhana. Oleh yang demikian, kaedah pengajaran dan pembelajaran didapati mempengaruhi peningkatan motivasi kerana muridmurid yang bermotivasi tinggi akan terus berusaha dan bersaing untuk mempelajari sesuatu mata pelajaran dengan baik, di samping membentuk sikap yang positif terhadap pelaksanaan sesuatu aktiviti pengajaran dan pembelajaran. Hal ini dapat dibuktikan melalui satu tinjauan awal yang dijalankan oleh 
pengkaji yang telah mendapati bahawa tahap motivasi intrinsik dalam kalangan murid tingkatan empat yang mengambil mata pelajaran sejarah adalah berada pada tahap sederhana (Kaviza, 2019).

Rentetan daripada itu, adalah tidak dapat disangkal bahawa penggunaan sumber-sumber sejarah dapat membentuk proses pengajaran dan pembelajaran sejarah yang berkesan dan menarik (Cowgill \& Waring, 2017; Nieuwenhuyse et al., 2017; Rantala \& Vanden, 2015; Renuka \& Siti Hawa, 2012; Nur Farah et al., 2015), namun sejauh mana penggunaan sumber-sumber tersebut berupaya untuk meningkatkan minat dan motivasi dalam kalangan murid masih belum diketahui walaupun dapatan kajian-kajian lepas telah melaporkan bahawa terdapat hubungan yang signifikan antara penggunaan multimedia iaitu dari segi kekerapan penggunaan, kepelbagaian penggunaan dan penggunaan sumber dalam pengajaran dan pembelajaran dengan minat pelajar terhadap mata pelajaran sejarah (Mohd Mahzan, Abdul Razaq \& Nur Syazwani, 2016) dan tahap kesediaan pembelajaran berasaskan sumber sejarah dari aspek pengetahuan, kemahiran dan sikap mempunyai hubungan linear positif yang amat tinggi secara signifikan terhadap motivasi intrinsik (Kaviza, Fauziah \& Nurliyana Bukhari, 2018). Justeru, kajian ini adalah bertujuan untuk mengenal pasti sama ada terdapat peningkatan motivasi terhadap penggunaan sumber-sumber sejarah berdasarkan Model Motivasi ARCS dalam kalangan murid.

\section{Objektif Kajian}

Secara khususnya, objektif utama kajian ini adalah untuk mengenal pasti sama ada terdapat perbezaan min motivasi antara ujian pra dan ujian pasca bagi murid-murid yang mengikuti pengajaran dan pembelajaran sejarah berasaskan penggunaan sumber-sumber sejarah berdasarkan Model Motivasi ARCS dari segi konstruk perhatian, konstruk perkaitan, konstruk keyakinan dan konstruk kepuasan.

\section{Soalan Kajian}

Secara khususnya, kajian ini ingin menjawab soalan kajian berikut:

i. Adakah terdapat perbezaan min motivasi antara ujian pra dan ujian pasca bagi murid-murid yang mengikuti pengajaran dan pembelajaran sejarah berasaskan penggunaan sumber-sumber sejarah berdasarkan Model Motivasi ARCS?

ii. Adakah terdapat perbezaan min konstruk perhatian antara ujian pra dan ujian pasca bagi murid-murid yang mengikuti pengajaran dan pembelajaran sejarah berasaskan penggunaan sumber-sumber sejarah?

iii. Adakah terdapat perbezaan min konstruk perkaitan antara ujian pra dan ujian pasca bagi murid-murid yang mengikuti pengajaran dan pembelajaran sejarah berasaskan penggunaan sumber-sumber sejarah?

iv. Adakah terdapat perbezaan min konstruk keyakinan antara ujian pra dan ujian pasca bagi murid-murid yang mengikuti pengajaran dan pembelajaran sejarah berasaskan penggunaan sumber-sumber sejarah?

v. Adakah terdapat perbezaan min konstruk kepuasan antara ujian pra dan ujian pasca bagi murid-murid yang mengikuti pengajaran dan pembelajaran sejarah berasaskan penggunaan sumber-sumber sejarah?

\section{Hipotesis Kajian}

Hipotesis nul yang dibentuk bagi menjawab soalan kajian berikut:

$\mathrm{H}_{\mathrm{ol}}$ : Tidak terdapat perbezaan yang signifikan min motivasi antara ujian pra dan ujian pasca bagi murid-murid yang mengikuti pengajaran dan pembelajaran sejarah berasaskan penggunaan sumbersumber sejarah berdasarkan Model Motivasi ARCS. 
$\mathrm{H}_{\text {ola }}$ : Tidak terdapat perbezaan yang signifikan min konstruk perhatian antara ujian pra dan ujian pasca bagi murid-murid yang mengikuti pengajaran dan pembelajaran sejarah berasaskan penggunaan sumber-sumber sejarah.

$\mathrm{H}_{\mathrm{olb}}$ : Tidak terdapat perbezaan yang signifikan min konstruk perkaitan antara ujian pra dan ujian pasca bagi murid-murid yang mengikuti pengajaran dan pembelajaran sejarah berasaskan penggunaan sumber-sumber sejarah.

$\mathrm{H}_{\mathrm{olc}}$ : Tidak terdapat perbezaan yang signifikan min konstruk keyakinan antara ujian pra dan ujian pasca bagi murid-murid yang mengikuti pengajaran dan pembelajaran sejarah berasaskan penggunaan sumber-sumber sejarah.

$\mathrm{H}_{\text {old: }}$ Tidak terdapat perbezaan yang signifikan min konstruk kepuasan antara ujian pra dan ujian pasca bagi murid-murid yang mengikuti pengajaran dan pembelajaran sejarah berasaskan penggunaan sumber-sumber sejarah.

\section{Metod Kajian}

Kajian eksperimen dengan reka bentuk Pre-Experimental Design: One Group Pretest-Posttest Design (Cohen, Manion \& Morrison, 2007) ini melibatkan 55 orang murid Tingkatan Empat yang dipilih melalui teknik persampelan cluster. Instrumen kajian ini merupakan soal selidik yang diadaptasi daripada Instructional Material Motivation Survey (Keller, 1983; 1987; 2010). Instrumen kajian tersebut juga telah disahkan oleh dua orang pakar penilai serta mempunyai nilai kebolehpercayaan Cronbach Alpha iaitu 0.92 yang dianggap baik dan boleh diterima dalam kajian ini (Nunnally, 1978). Kebenaran menggunakan instrumen kajian ini telah diperoleh daripada pembinaannya secara e-mel. Pengkaji dalam kajian ini telah mereka bentuk aktiviti pembelajaran berasaskan penggunaan sumbersumber sejarah bagi topik Tamadun Awal Manusia berdasarkan Model Motivasi ARCS. Data kajian ini telah dianalisis secara deskriptif dan inferensi iaitu ujian-t Sampel Berpasangan melalui perisian IBM SPSS Statistic.

\section{Dapatan Kajian}

\section{Perbezaan min motivasi antara ujian pra dan ujian pasca bagi murid-murid yang mengikuti pengajaran dan pembelajaran sejarah berasaskan penggunaan sumber- sumber sejarah berdasarkan Model Motivasi ARCS}

Berdasarkan Jadual 1, min motivasi bagi ujian pasca $(M=3.82, S D=0.44)$ adalah lebih tinggi berbanding dengan min ujian pra $(M=3.16, S D=0.53)$ bagi murid-murid yang mengikuti pengajaran dan pembelajaran sejarah berasaskan penggunaan sumber-sumber sejarah. Keputusan ujian-t Sampel Berpasangan pada Jadual 2 telah melaporkan bahawa terdapat perbezaan min motivasi yang signifikan antara ujian pra dan ujian pasca $[t(54)=-7.74, p=0.00]$ bagi murid-murid yang mengikuti pengajaran dan pembelajaran sejarah berasaskan penggunaan sumber-sumber sejarah. Justeru, $\mathrm{H}_{\mathrm{ol}}$ telah berjaya ditolak. Maka, dapat disimpulkan bahawa terdapat peningkatan min motivasi yang signifikan antara ujian pra dan ujian pasca bagi murid-murid yang mengikuti pengajaran dan pembelajaran sejarah berasaskan penggunaan sumber-sumber sejarah berdasarkan Model Motivasi ARCS dalam kajian ini.

Jadual 1: Statistik deskriptif bagi Min Motivasi

\begin{tabular}{llll}
\hline & $\boldsymbol{M}$ & $\mathbf{N}$ & $\boldsymbol{S D}$ \\
\hline Ujian Pra & 3.16 & 55 & 0.53 \\
Ujian Pasca & 3.82 & 55 & 0.44 \\
\hline
\end{tabular}


Jadual 2: Ujian-t Sampel Berpasangan bagi Min Motivasi

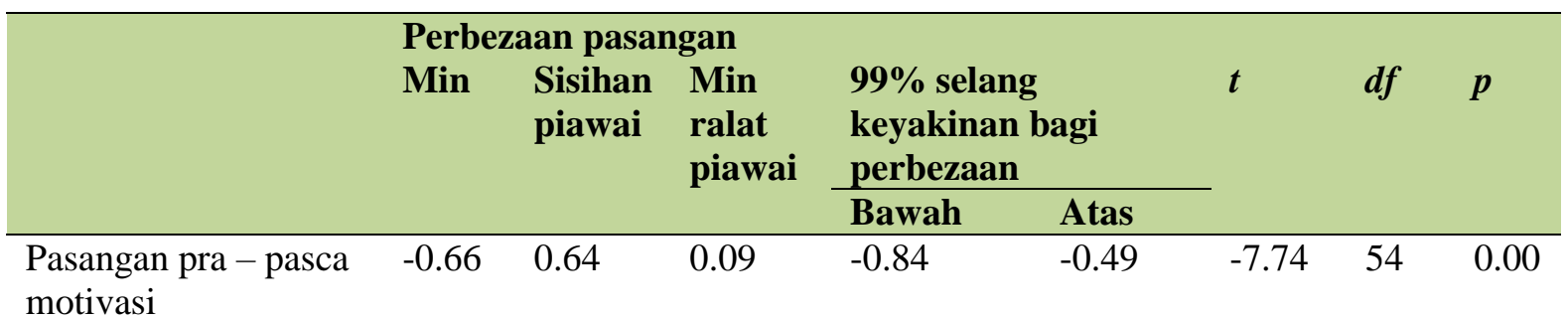

Perbezaan min perhatian antara ujian pra dan ujian pasca bagi murid-murid yang mengikuti pengajaran dan pembelajaran sejarah berasaskan penggunaan sumbersumber sejarah

Berdasarkan Jadual 3, min perhatian bagi ujian pasca $(M=3.78, S D=0.50)$ adalah lebih tinggi berbanding dengan min ujian pra $(M=2.96, S D=0.49)$ bagi murid-murid yang mengikuti pengajaran dan pembelajaran sejarah berasaskan penggunaan sumber-sumber sejarah. Keputusan ujian-t Sampel Berpasangan pada Jadual 4 telah melaporkan bahawa terdapat perbezaan min kepuasan yang signifikan antara ujian pra dan ujian pasca $[t(54)=-9.51, p=0.00]$ bagi murid-murid yang mengikuti pengajaran dan pembelajaran sejarah berasaskan penggunaan sumber-sumber sejarah. Justeru, $\mathrm{H}_{\mathrm{ola}}$ telah berjaya ditolak. Maka, dapat disimpulkan bahawa terdapat peningkatan min perhatian yang signifikan antara ujian pra dan ujian pasca bagi murid-murid yang mengikuti pengajaran dan pembelajaran sejarah berasaskan penggunaan sumber-sumber sejarah dalam kajian ini.

Jadual 3: Statistik deskriptif bagi Min Perhatian

\begin{tabular}{llll}
\hline & $\boldsymbol{M}$ & $\mathbf{N}$ & $\boldsymbol{S D}$ \\
\hline Ujian Pra & 2.96 & 55 & 0.49 \\
Ujian Pasca & 3.78 & 55 & 0.50 \\
\hline
\end{tabular}

Jadual 4: Ujian-t Sampel Berpasangan bagi Min Perhatian

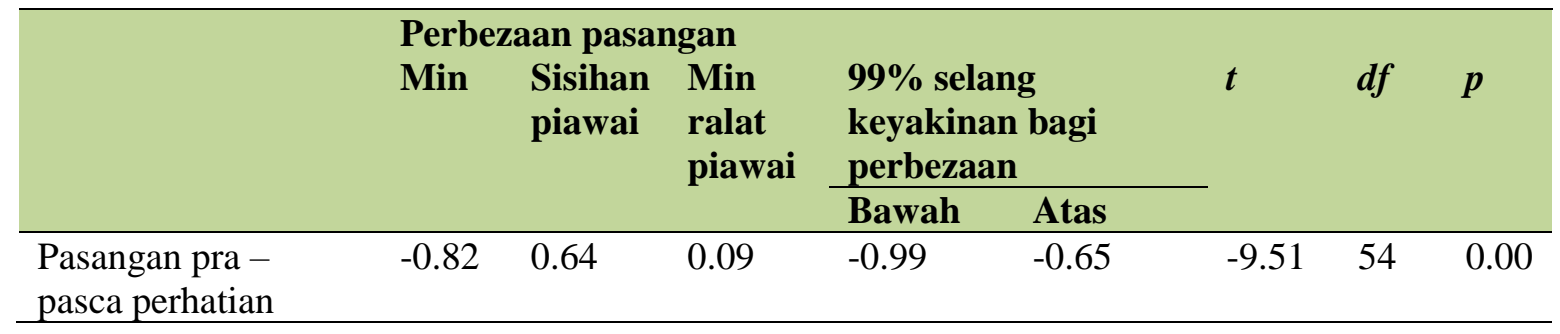

\section{Perbezaan min perkaitan antara ujian pra dan ujian pasca bagi murid-murid yang mengikuti pengajaran dan pembelajaran sejarah berasaskan penggunaan sumber- sumber sejarah}

Berdasarkan Jadual 5, min perkaitan bagi ujian pasca $(M=3.91, S D=0.51)$ adalah lebih tinggi berbanding dengan min ujian pra $(M=3.21, S D=0.66)$ bagi murid-murid yang mengikuti pengajaran dan pembelajaran sejarah berasaskan penggunaan sumber-sumber sejarah. Keputusan ujian-t Sampel Berpasangan pada Jadual 6 telah melaporkan bahawa terdapat perbezaan min perkaitan yang signifikan antara ujian pra dan ujian pasca $[t(54)=-6.62, p=0.00]$ bagi murid-murid yang mengikuti pengajaran dan pembelajaran sejarah berasaskan penggunaan sumber-sumber sejarah. Justeru, $\mathrm{H}_{\mathrm{olb}}$ telah berjaya ditolak. Maka, dapat disimpulkan bahawa terdapat peningkatan min perkaitan yang signifikan antara ujian pra dan ujian pasca bagi murid-murid yang mengikuti pengajaran dan pembelajaran sejarah berasaskan penggunaan sumber-sumber sejarah dalam kajian ini. 
DOI: https://doi.org/10.47405/mjssh.v5i7.923

Jadual 5: Statistik deskriptif bagi Min Perkaitan

\begin{tabular}{llll}
\hline & $\boldsymbol{M}$ & $\mathbf{N}$ & $\boldsymbol{S D}$ \\
\hline Ujian Pra & 3.21 & 55 & 0.66 \\
Ujian Pasca & 3.91 & 55 & 0.51 \\
\hline
\end{tabular}

Jadual 6: Ujian-t Sampel Berpasangan bagi Min Perkaitan

\begin{tabular}{|c|c|c|c|c|c|c|c|c|}
\hline & \multicolumn{8}{|c|}{ Perbezaan pasangan } \\
\hline & \multirow[t]{2}{*}{ Min } & \multirow[t]{2}{*}{$\begin{array}{l}\text { Sisihan } \\
\text { piawai }\end{array}$} & \multirow[t]{2}{*}{$\begin{array}{l}\text { Min } \\
\text { ralat } \\
\text { piawai }\end{array}$} & \multicolumn{2}{|c|}{$\begin{array}{l}99 \% \text { selang } \\
\text { keyakinan bagi } \\
\text { perbezaan }\end{array}$} & \multirow[t]{2}{*}{$t$} & \multirow[t]{2}{*}{$d f$} & \multirow[t]{2}{*}{$p$} \\
\hline & & & & Bawah & Atas & & & \\
\hline $\begin{array}{l}\text { Pasangan pra - pasca } \\
\text { perkaitan }\end{array}$ & -0.70 & 0.78 & 0.10 & -0.91 & -0.49 & -6.62 & 54 & 0.00 \\
\hline
\end{tabular}

Perbezaan min keyakinan antara ujian pra dan ujian pasca bagi murid-murid yang mengikuti pengajaran dan pembelajaran sejarah berasaskan penggunaan bahanbahan sejarah

Berdasarkan Jadual 7, min keyakinan bagi ujian pasca $(M=3.65, S D=0.64)$ adalah lebih tinggi berbanding dengan min ujian pra $(M=3.16, S D=0.53)$ bagi murid-murid yang mengikuti pengajaran dan pembelajaran sejarah berasaskan penggunaan sumber-sumber sejarah. Keputusan ujian-t Sampel Berpasangan pada Jadual 8 telah melaporkan bahawa terdapat perbezaan min keyakinan yang signifikan antara ujian pra dan ujian pasca $[t(54)=-4.71, p=0.00]$ bagi murid-murid yang mengikuti pengajaran dan pembelajaran sejarah berasaskan penggunaan sumber-sumber sejarah. Justeru, $\mathrm{H}_{\mathrm{olc}}$ telah berjaya ditolak. Maka, dapat disimpulkan bahawa terdapat peningkatan min keyakinan yang signifikan antara ujian pra dan ujian pasca bagi murid-murid yang mengikuti pengajaran dan pembelajaran sejarah berasaskan penggunaan sumber-sumber sejarah dalam kajian ini.

Jadual 7: Statistik deskriptif bagi Min Keyakinan

\begin{tabular}{llll}
\hline & $\boldsymbol{M}$ & $\mathbf{N}$ & $\boldsymbol{S D}$ \\
\hline Ujian Pra & 3.12 & 55 & 0.57 \\
Ujian Pasca & 3.65 & 55 & 0.64 \\
\hline
\end{tabular}

Jadual 8: Ujian-t Sampel Berpasangan bagi Min Keyakinan

\begin{tabular}{|c|c|c|c|c|c|c|c|c|}
\hline & \multicolumn{8}{|c|}{ Perbezaan pasangan } \\
\hline & \multirow[t]{2}{*}{ Min } & \multirow[t]{2}{*}{$\begin{array}{l}\text { Sisihan } \\
\text { piawai }\end{array}$} & \multirow[t]{2}{*}{$\begin{array}{l}\text { Min } \\
\text { ralat } \\
\text { piawai }\end{array}$} & \multicolumn{2}{|c|}{$\begin{array}{l}99 \% \text { selang } \\
\text { keyakinan bagi } \\
\text { perbezaan }\end{array}$} & \multirow[t]{2}{*}{$t$} & \multirow[t]{2}{*}{$d f$} & \multirow[t]{2}{*}{$p$} \\
\hline & & & & Bawah & Atas & & & \\
\hline $\begin{array}{l}\text { Pasangan pra-pasca } \\
\text { keyakinan }\end{array}$ & -0.54 & 0.84 & 0.11 & -0.76 & -0.31 & -4.71 & 54 & 0.00 \\
\hline
\end{tabular}

Perbezaan min kepuasan antara ujian pra dan ujian pasca bagi murid-murid yang mengikuti pengajaran dan pembelajaran sejarah berasaskan penggunaan sumbersumber sejarah

Berdasarkan Jadual 9, min kepuasan bagi ujian pasca $(M=4.00, S D=0.64)$ adalah lebih tinggi berbanding dengan min ujian pra $(M=3.16, S D=0.53)$ bagi murid-murid yang mengikuti pengajaran dan pembelajaran sejarah berasaskan penggunaan sumber-sumber sejarah. Keputusan ujian-t Sampel Berpasangan pada Jadual 10 telah melaporkan bahawa terdapat perbezaan min kepuasan yang 
signifikan antara ujian pra dan ujian pasca $[t(54)=-3.61, p=0.00]$ bagi murid-murid yang mengikuti pengajaran dan pembelajaran sejarah berasaskan penggunaan sumber-sumber sejarah. Justeru, $\mathrm{H}_{\text {old }}$ telah berjaya ditolak. Maka, dapat disimpulkan bahawa terdapat peningkatan min kepuasan yang signifikan antara ujian pra dan ujian pasca bagi murid-murid yang mengikuti pengajaran dan pembelajaran sejarah berasaskan penggunaan sumber-sumber sejarah dalam kajian ini.

Jadual 9: Statistik deskriptif bagi Min Kepuasan

\begin{tabular}{llll}
\hline & $\boldsymbol{M}$ & $\mathbf{N}$ & $\boldsymbol{S D}$ \\
\hline Ujian Pra & 3.52 & 55 & 0.88 \\
Ujian Pasca & 4.00 & 55 & 0.64 \\
\hline
\end{tabular}

Jadual 10: Ujian-t Sampel Berpasangan bagi Min Kepuasan

\begin{tabular}{|c|c|c|c|c|c|c|c|c|}
\hline & \multicolumn{8}{|c|}{ Perbezaan pasangan } \\
\hline & \multirow[t]{2}{*}{ Min } & \multirow[t]{2}{*}{$\begin{array}{l}\text { Sisihan } \\
\text { piawai }\end{array}$} & \multirow[t]{2}{*}{$\begin{array}{l}\text { Min } \\
\text { ralat } \\
\text { piawai }\end{array}$} & \multicolumn{2}{|c|}{$\begin{array}{l}99 \% \text { selang } \\
\text { keyakinan bagi } \\
\text { perbezaan }\end{array}$} & \multirow[t]{2}{*}{$t$} & \multirow[t]{2}{*}{$d f$} & \multirow[t]{2}{*}{$p$} \\
\hline & & & & Bawah & Atas & & & \\
\hline $\begin{array}{l}\text { Pasangan pra - pasca } \\
\text { kepuasan }\end{array}$ & -0.49 & 1.00 & 0.14 & -0.76 & -0.22 & -3.61 & 54 & 0.00 \\
\hline
\end{tabular}

\section{Perbincangan Kajian}

Dapatan kajian ini yang menunjukkan bahawa terdapat perbezaan yang signifikan terhadap motivasi antara ujian pra dan ujian pasca bagi murid-murid yang mengikuti pengajaran dan pembelajaran Sejarah berasaskan penggunaan sumber-sumber sejarah adalah selari dengan kajian Mohd Mahzan, Abdul Razaq dan Nur Syazwani (2016) yang telah melaporkan bahawa penggunaan multimedia dalam pendidikan sejarah mempunyai hubungan yang signifikan dengan minat belajar sejarah dalam kalangan murid. Sungguhpun begitu, penggunaan sumber sejarah dalam kajian ini yang dapat meningkatkan penyertaan aktif dalam sesi pengajaran dan pembelajaran melalui tugasan dan aktiviti pembelajaran telah memberikan kesan afektif dari segi persediaan, hasil dan minat yang positif adalah sealiran dengan dapatan kajian yang dijalankan oleh Niewenhuyse et al. (2017) yang telah melaporkan bahawa penggunaan sumber primer sebagai prompt penaakulan dapat membentuk proses pengajaran dan pembelajaran Sejarah yang menarik. Selain itu, penyertaan aktif murid yang dapat meningkatkan naluri ingin tahu dan minat melalui penggunaan sumber sejarah dalam kajian ini adalah sealiran dengan dapatan kajian Pivkina, Ranjan dan Loddr (2009) serta Cowgill II (2015) yang menjelaskan kepentingan penggunaan sumber sejarah sebagai bahan pengajaran bagi membentuk proses inkuiri di dalam kelas.

Tambahan pula, konstruk-konstruk dalam motivasi seperti perhatian, perkaitan, keyakinan dan kepuasan yang turut menunjukkan perbezaan yang signifikan antara ujian pra dan ujian pasca dalam kalangan murid yang mengikuti pengajaran dan pembelajaran sejarah berasaskan penggunaan sumber sejarah dalam kajian ini adalah selaras dengan Model Motivasi ARCS (Keller, 1983; 1987) yang menjelaskan bahawa penerokaan sumber sejarah dengan mengkaji persoalan-persoalan sejarah yang diutarakan dapat membangkitkan minat murid untuk terus menyiasat peristiwa sejarah tersebut dengan meningkatkan naluri ingin tahu melalui tugasan-tugasan pembelajaran yang direka bentuk. Hal ini kerana apabila murid-murid mengetahui tujuan dan matlamat pemupukan sesuatu kemahiran dan pengetahuan dalam proses pengajaran dan pembelajaran, maka segala ilmu-ilmu tersebut dapat diaplikasikan ke dalam konteks kehidupan sebenar dan mereka akan cuba untuk menghargai dan mengamalkannya sepanjang hayat. Perkara ini adalah bertepatan dengan penggunaan sumber sejarah dalam proses pengajaran dan pembelajaran Sejarah yang dapat membantu murid-murid untuk memahami sesuatu ilmu sejarah yang dapat dijadikan sebagai pengajaran dan tauladan secara tidak langsung (Noor Norazila, Mahzan \& Abdul Razaq, 2016; Straaten, Wilschut \& Oostden, 2015) yang 
akhirnya juga dapat meningkatkan pencapaian akademik mereka seperti ditetapkan dalam kurikulum Sejarah (PPK, 2003).

\section{Kesimpulan}

Implikasi kajian ini menunjukkan kepelbagaian pendekatan, strategi dan kaedah pengajaran dapat meningkatkan motivasi yang tinggi sekiranya ianya dapat diterapkan dan diaplikasikan dalam proses pengajaran dan pembelajaran dengan lebih baik. Justeru, kajian ini mendapati bahawa penggunaan sumber-sumber sejarah dapat meningkatkan motivasi dalam kalangan murid Tingkatan Empat yang telah mencadangkan kepada guru-guru Sejarah untuk mengintegrasikan penggunaan sumber-sumber sejarah dalam konteks pengajaran dan pembelajaran di dalam kelas sebagai alternatif kepada kaedah pengajaran sedia ada yang bertujuan untuk menarik minat dan meningkatkan motivasi dalam kalangan murid. Hal ini kerana proses pengajaran dan pembelajaran Sejarah yang menggalakkan pemupukan nilai-nilai murni, jati diri, patriotisme dan sebagainya yang memerlukan penghayatan, kreativiti serta pemikiran kritis dapat dicapai sekiranya murid-murid mempunyai tahap motivasi yang tinggi. Selain itu, penggunaan bahan-bahan pengajaran dan pembelajaran khususnya penggunaan sumber-sumber sejarah dalam kajian ini adalah berupaya untuk menjadikan proses pengajaran dan pembelajaran Sejarah lebih menarik, interaktif dan bersesuaian dengan arus perkembangan sistem pendidikan Malaysia melalui Pelan Pembangunan Pendidikan Malaysia 2013-2025 yang memfokuskan kepada perubahan dalam kaedah pengajaran dan pembelajaran (KPM, 2013).

\section{Rujukan}

Abdul Rahim Abdul Rashid. (2000). Model dan Pendekatan Pengajaran Sejarah KBSM. Kuala Lumpur: Dewan Bahasa dan Pustaka

Aizu Khalili Zohedi, Nor Hasbiah Ubaidullah \& Norasikin Fabil. (2017). Aplikasi Prinsip Exaggeration, Kemahiran Berfikir Kritis dan Kreatif serta Model Motivasi ARCS Terhadap Topik Integer Matematik Tingkatan Satu. Journal of ICT in Education, 4, 52-65.

Ambika Luhitadati, Maskun \& Suparman Arif. (2017). Hubungan Motivasi Berprestasi dengan Hasil Belajar Siswa pada Mata Pelajaran sejarah. Jurnal Pendidikan dan Penelitian Sejarah, 5(8), 1-12.

Ch'ng, S. H. (2005). Penggunaan ICT Untuk Memperkembangkan Pengetahuan, Kreativiti Dan Minat Terhadap Mata Pelajaran Sejarah Tingkatan Empat. Tesis Sarjana Universiti Malaya.

Cohen, L., Manion, L., \& Morrison, K. (2007). Research Methods in Education (6 ${ }^{\text {th }}$ Edition). London: Routledge Falmer.

Cowgill II, D.A. (2015). Primary Sources in the social studies classroom: Historical inquiry with book backrops. Social Studies Research and Practice, 10(1), 65-83.

Cowgill II, D.A., \& Waring, S.M. (2017). Historical Thinking: An Evaluation of Student and Teacher Ability to Analyze Sources. Journal of Social Studies Education Research, 8(1), 115-145.

Fadzilah Sulaiman (2010). Keberkesanan Aplikasi Teori Kecerdasan Pelbagai Untuk Meningkatkan Pencapaian Dan Motivasi Pelajar Berpencapaian Akademik Rendah Dalam Mata Pelajaran Sejarah. Tesis Sarjana Universiti Kabangsaan Malaysia.

Hazri Jamil. (2003). Teknik mengajar Sejarah. Pahang: PTS Publications \& Distributors

Hover, S.V., Hicks, D., \& Dack, H. (2016). From Source to Evidence? Teachers' Use of Historical Sources in Their Classrooms. The Social studies, 107(6), 209-217.

Johansson, P. (2017). Learning study as a clinical research practice to generate knowledge about the learning of historical primary source analysis. Educational Action Research, 25(1), 167-181.

Kaviza, M, Fauziah Abdul Rahim, \& Nurliyana Bukhari. (2018). Hubungan antara Kesediaan dalam Pembelajaran Berasaskan Sumber-sumber Sejarah dengan Motivasi Intrinsik. Jurnal Pendidikan Bitara UPSI, 11(1), 52-63.

Kaviza, M. (2019). Motivasi Instrinsik dalam kalangan murid tingkatan empat yang mengambil mata pelajaran sejarah. International Journal of Education, Pscychology and Counseling, 4(31), 215224.

Keller, J.M. (1983). Motivational Designs of Instruction, Instructional Design Theories and Models. Hillsdale, New Jersey: Erlbaum. 
Keller, J.M. (1987). Development and use of the ARCS Model of motivational Design. Journal of Instructional Development, 10(3), 2-11.

Keller, J.M. (2010). Motivational Design for Learning and Performance: The ARCS Model Approach. New York: Springer

Kementerian Pendidikan Malaysia. (2013). Pelan Pembangunan Pendidikan Malaysia 2013-2025. Putrajaya: Kementerian Pendidikan Malaysia.

Malone, T.W., \& Lepper, M.R. (1988). Making Learning fun: A taxonomy of intrinsic motivations for learning. In R.E. Snow and M.J. Farr. (Eds). Aptitude, Learning and Instructiona 3. Cognitive and affective process analyses. (pp.229-153). Hillsdale, New Jersey: Erlbaum.

Mohd Mahzan Awang, Abdul Razaq Ahmad, \& Nur Syazwani Abdul Talib. (2016). Penggunaan Multimedia Dalam Pendidikan Sejarah Pada Abad Ke-21 dan Hubungannya Dengan Minat Belajar Sejarah. Jurnal Pemikir Pendidikan, 7, 44-56.

Nieuwenhuyse, K.V., Roose, H., Wils, K., Depaepe, F., Verschaffel, L. (2017). Reasoning with and /or about sources? The use of primary sources in Flemish Secondary school history education. Journal of Historical consciousness, historical cultures and history education, 48-70.

Noor Norazila Inai, Mahzan Awang \& Abdul Razaq Ahmad, (2016). Pembinaan Kerangka Konsep Terhadap Penerimaan Kurikulum Sejarah dan Hubungannya dengan Motivasi Pelajar. Kertas kerja yang dibentangkan di International Conference on Education and Regional Development (ICERD 2016), 31 Oktober \& 1 November, Bandung, Indonesia.

Nunnally, J.C. (1978). Psychometrie Theory ( $2^{\text {nd }}$ Ed). New York: McGraw Hill.

Nur Farah Fasihah Komaro, Komari Hussain, Dara Rugayah ramli, Mahzan Awang \& Zuriah Ibrahim (2015). Tahap Penggunaan Sumber Sejarah, Minat dan penggunaan sumber sejarah oleh guru sekolah rendah: Kajian perbandingan Malaysia dan Indonesia. Proceeding $6^{\text {th }}$ Pedagogy International Seminar 2015.

Nur Syazwani Abdul talib, Kamarul zaman Abdul Ghani \& Nur Azuki Yusuff. (2016). Tahap pengetahuan dan sikap graduan IPT serta hubungannya dengan minat terhadap sejarah: usaha awal memupuk semanagt cinta negara. Jurnal Pemikir Pendidikan, 7, 57-72.

Omardin Haji Ashaari \& Yunus Muhammad. (1996). Kaedah Pengajaran Sejarah. Kuala Lumpur: Utusan Publication and Distributor Sdn Bhd.

Patterson, N.C., Lucas, A.G., \& Kithinji, M. (2012). Higher Order Thinking in Social Studies: An analysis of Primary Source Document Use. Social studies Research and Practice, 7(2), 68-85.

Pivkina, I., Ranjan, D., \& Loddr, J. (2009). Historical Sources as aTeaching Tool. Kertas kerja yang dibentangkan di SIGCSE'09, March 3-7, Chattanooga, Tennessee, USA.

Pusat Perkembangan Kurikulum. (2003). Huraian Sukatan Pelajaran Sejarah Tingkatan Empat. Kuala Lumpur: Kementerian Pendidikan Malaysia.

Rantala, J. \& Van Den Berg, M. (2015). Finnish high school and university students' ability to handle multiple source documents in history. Historical Encounters: A Journal of Historical Consciousness, historical cultures and history education, 2(1), 70-88.

Reisman, A., \& Fogo, B. (2016). Contributions of Educative document based curricular materials to quality of historical instruction. Teaching and Teacher Education, 59, 191-202.

Renuka Ramakrishnan \& Siti Hawa Abdullah. (2012, Oktober). Penggunaan Sumber Digital Dalam Kalangan Guru Sejarah. Kertas kerja yang dibentangkan di Seminar Kebangsaan Majlis Dekan Pendidikan IPTA, The Zon Regency by the Sea, Johor Bharu, Malaysia.

Sri Wahyuni Marimun \& Anuar Ahmad. (2019). Tahap Kesediaan Pelajar Melayu Mempelajari Sejarah di Sekolah Aliran Cina (SRJKC) menggunakan bahasa Mandarin dan hubungannya dengan pencapaian. International Journal of Humanities, Philosophy and Language, 2(7), 93-106.

Straaten, D.V., Wilschut, A., \& Oostdam, R. (2015). Making history relevant to students by connecting past, present and future: A framework for research. Journal of Curriculum Studies, 125 .

Suntharalingam. (1985). Pengenalan Kepada Sejarah. Kuala Lumpur: Marican \& Sons

Toh, S.C. (1998). Cognitive and Motivational Effects of two Multimedia Simulation Presentation Modes o $n$ Science Learning. Tesis kedoktoran Universiti Sains Malaysia yang tidak diterbitkan.

Wineburg, S. (1991b). Historical problem solving: A study of the cognitive processes used in the evaluation of documentary and pictorial evidence. Journal of Educational Psychology, 83, 73-87.

Wineburg, S.S. (1991a). On the Reading of Historical Texts: Notes on the Breach between School and Academy. American Educational Research Journal, 28(3), 495-519. 